\title{
Quick Scan of Suicide and its Danger Signs
}

\author{
Susheelkumar V Ronad ${ }^{1 *}$, Chetan S Patali², Shridhar H Gondbal ${ }^{3}$, Kirankumar TC ${ }^{4}$, Pankaja TC ${ }^{5}$, Rajendra \\ Badesgol $^{6}$, Veeresh Nandgaon ${ }^{7}$ and Timmapur TM ${ }^{8}$
}

${ }^{1}$ Department of Psychiatric Nursing DIMHANS Dharwad, India

${ }^{2}$ Principal, Dhanush Institute Of Nursing Sciences, India

${ }^{3}$ Staff Nurse, Indira Gandhi Children's Hospital, India

${ }^{4}$ Department of Management Studies, , India

${ }^{5}$ RL Law College, India

${ }^{6}$ Department of Police, India

${ }^{7}$ KLE Institute of Nursing Sciences Belgaum, India

${ }^{8}$ Psychiatric Social Worker, , India

*Corresponding author: Susheelkumar V Ronad, Department of Psychiatric Nursing DIMHANS Dharwad, India

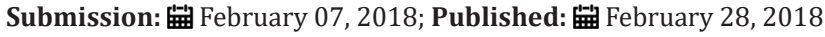

\section{Editorial}

As the $10^{\text {th }}$ leading cause of death in the United States and the second leading cause of death for people aged 15 to 34, suicide is a serious public health problem. Each year, more than 40,000 people die by suicide (one every 15 minutes) and 1 million people attempt suicide, according to the Centers for Disease Control and Prevention. Men are nearly four times more likely than women to take their lives. Yet, suicide can be preventable. Knowing the risk factors and recognizing the warning signs for suicide can help reduce the suicide rate.

\section{Risk Factors, Warning Signs and Protective Factors}

A. Suicide is linked to mental disorders, particularly depression and alcohol use disorders, and the strongest risk factor for suicide is a previous suicide attempt.

B. The Suicide Prevention Resource Center defines risk and protective factors and warning signs:

C. Risk factors are characteristics that make it more likely that an individual will consider, attempt or die by suicide.

D. Protective factors are characteristics that make it less likely that individuals will consider, attempt or die by suicide.

\section{Warning Signs Indicate an Immediate Risk of Suicide}

Warning Signs of Suicide as follows

A. Often talking or writing about death, dying, or suicide

B. Making comments about being hopeless, helpless or worthless

C. Expressions of having no reason for living; no sense of purpose in life; saying things like "It would be better if I wasn't here" or "I want out"

D. Increased alcohol and/or drug misuse

E. Withdrawal from friends, family and community

F. Reckless behavior or more risky activities, seemingly without thinking

G. Dramatic mood changes

H. Talking about feeling trapped or being a burden to others

In some cases, an immediate stressor or sudden catastrophic event, failure or humiliation like a relationship break-up, legal problems, financial problems (e.g., home foreclosure or job loss) can leave people feeling desperate, unable to see a way out, and become a "tipping point" toward suicide.

If someone indicates they are considering suicide, listen and take their concerns seriously. Don't be afraid to ask questions about their plans. Let them know you care, and they are not alone. Encourage them to seek help immediately from a knowledgeable professional. Don't leave them alone.

If you need help, please call the National Suicide Prevention Lifeline at 1-800-273-TALK (8255) or go to www. suicidepreventionlifeline.org and Click to Chat

\section{Risk Factors for Suicide}

A. Certain events and circumstances may increase risk.

B. Previous suicide attempt(s)

C. A history of suicide in the family 
D. Substance misuse

E. Mood disorders (depression, bipolar disorder)

F. Access to lethal means (e.g., keeping firearms in the home)

G. Losses and other events (for example, the breakup of a relationship or a death, academic failures, legal difficulties, financial difficulties, bullying)

H. History of trauma or abuse

I. Chronic physical illness, including chronic pain

J. Exposure to the suicidal behavior of others

\section{Protective Factors}

Effective mental health care; easy access to a variety of clinical interventions

Strong connections to individuals, family, community and social institutions

Problem-solving and conflict resolution skills
Contacts with providers (e.g., follow-up phone call from health care professional)

As with mental illness, one of the biggest barriers to preventing suicide is stigma, which prevents many people from seeking help.

\section{Resources}
A. American Association of Suicidology
B. Veteran's Administration Suicide Prevention
C. American Foundation for Suicide Prevention (AFSP)
D. International Association for Suicide Prevention (IASP)
E. 2015 World Suicide Prevention Day fact sheet
F. WHO - Suicide Prevention
G. World Suicide Report: Preventing Suicide, A Global Imperative

\section{H. Suicide Prevention Resource Center}

Your subsequent submission with Crimson Publishers will attain the below benefits

- High-level peer review and editorial services

- Freely accessible online immediately upon publication

- Authors retain the copyright to their work

- Licensing it under a Creative Commons license

- Visibility through different online platforms

- Global attainment for your research

- Article availability in different formats (Pdf, E-pub, Full Text)

- Endless customer service

- Reasonable Membership services

- Reprints availability upon request

- One step article tracking system 